\title{
Modelling of the aluminium alloy machining process
}

\author{
Piotr Paszta ${ }^{1, *}$ \\ ${ }^{1}$ Faculty of Mechanical Engineering and Computer Science, Czestochowa University of Technology, \\ Al. Armii Krajowej 21, 42-200 Czestochowa, Poland
}

\begin{abstract}
The article presents the possibility of modelling the process of turning aluminium alloy 2017. It reports obtained results for the distribution of stress and temperature in the machining zone. Tests for assumed machining parameters were performed on a CNC machine tool. Microscopic photographs of the turned surface are shown. Top surface measurements were taken on a computerize measuring stand including a New Form Talysurf 2D/3D 120 Taylor Hobson profilometer.
\end{abstract}

\section{Introduction}

Machining is one of the most widespread material working types, being part of the process of manufacturing elements of many technical devices. During machining, the workpiece obtains the required shapes and dimensions and the desired surface quality. The process progresses in a very dynamic manner, violent stresses and elastic and plastic strains form in the machined material and temperature changes occur in the machining zone, there occurs also friction, chip upsetting, material hardening, and sometimes accretion forms.

The main drawback of subtractive manufacturing is the formation of waste material in the form of chips. Very often, this is the only material working method available, impossible to be substituted or eliminated. It provides the required accuracy and top surface finish at low expenditure. A rapid development of machining tools, instrumentation, CNC machines has taken place in recent years, along with their wide dissemination, even in minor plants. A greater proportion of machining with small allowances and finishing machining is visible.

A group of aluminium alloys has found wide application in engineering. By adding alloying elements to aluminium, we can markedly improve its mechanical properties and machinability. The main aluminium alloy additions include copper, silicon, magnesium, zinc and lithium. Aluminium alloys have a low mass density and an advantageous strength to weight ratio. Aluminium alloys are categorized into wrought alloys and casting alloys. In respect of processing technology, these groups may overlap. Alloy 2017 finds wide application in subtractive manufacturing owing to its slight contents of insoluble elements, such as lead and bismuth, forming dispersed particles within the microstructure, which facilitate the chip forming process.

\footnotetext{
*Corresponding author: paszta@itm.pcz.pl
} 
The increased concentration of copper and magnesium enhances the tensile strength and hardness and heat resistance, impairs ductility and slightly reduces the corrosion resistance. Alloys from this group are willingly used in the aircraft and automotive industries. They find application in the manufacture of car and aircraft wheel rings, aircraft bearing elements and fuselages and responsible structural parts, car and aircraft engine parts, as well as engine equipment parts, such as turbine and compressor impellers, and engine cylinder heads operating at elevated temperatures.

Aluminium alloys melt at a temperature of $550-650^{\circ} \mathrm{C}$. In alloys with a large content of silicon, partial melting of the machined surface may occur. Owing to the lower thermal and mechanical loads during machining of duralumin, increased machining speeds can be used. Overheating during machining may result in a drop in the strength of the part being machined. To prevent this, cooling should be used during machining [1,2].

Aluminium alloys are well machinable. To evaluate the machinability of a given alloy, it is necessary to subject it to machining, assess the tool wear and chip shape, and then choose the appropriate machining parameters. When relaying on catalogue machining parameter selection data, they should be constantly optimized experimentally.

\section{Numerical modelling results}

During machining of aluminium and its alloys, a temperature of up to approx. $550^{\circ} \mathrm{C}$, thus being close to the melting point, can be generated. An example is modelling of the process of machining aluminium 7075 (Figure 1). A DCGT T304 solid carbide cutting plate was employed. Adopted machining parameters conforming to the catalogue data for the machined material and the cutting plate were as follows: machining speed, $\mathrm{Vc}=300 \mathrm{~m} / \mathrm{min}$, machining depth, $\mathrm{ap}=2.5 \mathrm{~mm}$, synchronous feed, $\mathrm{ft}=0.25 \mathrm{~mm} / \mathrm{rev}$. The material used for machining was an aluminium alloy having high mechanical strength, comparable to that of constructional steels, and very high fatigue strength. It has very good machinability and a hardness of up to $190 \mathrm{HB}$. It has moderate corrosion resistance. The alloy is used for making blow moulds, plastic foaming moulds, stamping and blanking die elements, as well as in the aircraft industry for making heavily loaded structural elements and for production of sports equipment.

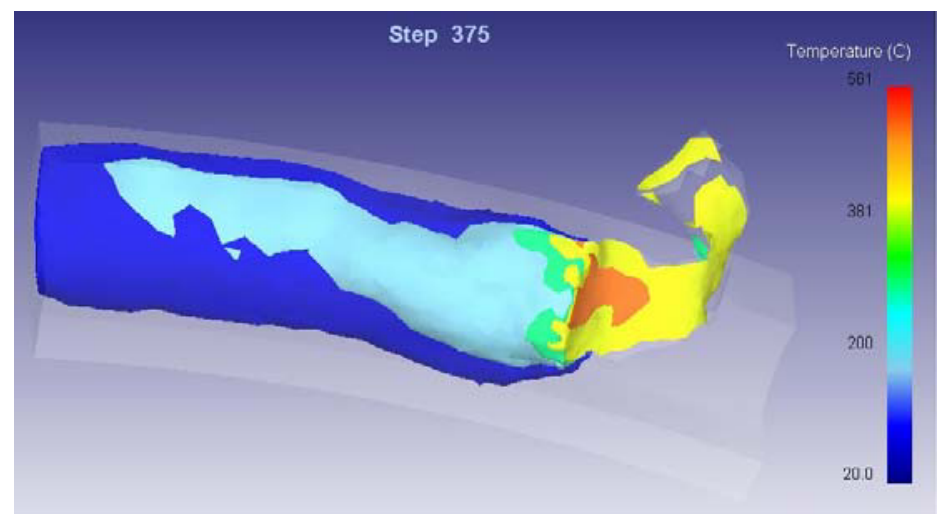

Fig. 1. The modelling outcome - aluminium alloy 7075 temperature distribution.

Nowadays, every machining process requires modelling, analysis and often verification by numerical methods. It is possible to select the appropriate tool geometry, feed parameters, rotational speed and machining depth. For machining aluminium, polycrystalline diamond and coated sintered carbide plates are used. 
There many programs that utilize the Finite Element Method (FEM) aiding CAX engineering work. One of them is DEFORM 3D. It offers a number of systems and modules that enable a comprehensive analysis of manufacturing processes. This is a flexible software application that enables one to analyze a wide range of deformations, thermal processes and microstructure [3, 4].

The system can be used for modelling of machining processes. The program procedures enable modelling of engineering processes, the selection of boundary conditions, and allow the analysis of the process for any change in process conditions. With its use, for example, the following can also be computed: machining force, temperature in the tool and material contact zone, chip shapes, or material wear. The effect of machining process parameters, such as machining speed, feeds and machining depth, can be examined.

In the simulation of the duralumin machining process, the Johnson-Cook constitutive model was employed, which enables the yield stress to be calculated from the following formula $[5,6]$ :

$$
\begin{gathered}
\bar{\sigma}=\bar{\sigma}(\bar{\varepsilon}, \dot{\bar{\varepsilon}}, T) \\
\bar{\sigma}=\left(A+B \bar{\varepsilon}^{n}\right)\left(1+C \ln \left(\frac{\dot{\bar{\varepsilon}}}{\overline{\overline{\varepsilon_{0}}}}\right)\right)\left(\frac{\dot{\bar{\varepsilon}}}{\overline{\overline{\varepsilon_{0}}}}\right)^{\alpha}\left(1-T^{* m}\right) T^{*}=\left(\frac{T-T_{\text {room }}}{T_{\text {melt }}-T_{\text {room }}}\right)
\end{gathered}
$$

Where: A, B, C, m, n, $\alpha$ are dimensionless material constants, $\mathrm{T}_{\text {melt }}$ - material melting point, $\mathrm{T}_{\text {room }}$ - reference temperature, $\mathrm{T}$ - workpiece temperature, $\bar{\varepsilon}$ - effective plastic strain, $\dot{\bar{\varepsilon}}$ - effective plastic strain rate, $\dot{\overline{\varepsilon_{0}}}-$ reference effective plastic strain rate.

The functions used in the Johnson-Cook model represent the effect of different factors on the magnitude of $\bar{\sigma}$ yield stress in the material of the workpiece shaped during machining. These are: strain hardening, plastic strain rate, material susceptibility to strain rate and the effect of temperature [7].

Material used for simulation was aluminium alloy 2017. The Usui tool wear model was adopted in the simulation. The coefficients used in the model rely on experimental relationships and are dependent on the process conditions and the materials used $[6,8,9]$. Then, a database was generated and simulation of the turning process was performed for the following parameters: machining depth, ap=1 mm, turning diameter $48 \mathrm{~mm}$, rotational speed $5400 \mathrm{rpm}$, synchronous feeds $\mathrm{ft} 1=0.1 \mathrm{~mm} / \mathrm{rev}$ and $\mathrm{ft} 2=0.01 \mathrm{~mm} / \mathrm{rev}$. Upon completion of the simulation, the following results were obtained. Figure 2 shows the distribution of normal stress for a feed of $0.1 \mathrm{~mm} / \mathrm{rev}$ and $0.01 \mathrm{~mm} / \mathrm{rev}$, respectively. Figure 3 illustrates the distribution of machined material temperatures, while Figure 4 shows the tool cutting edge temperature.
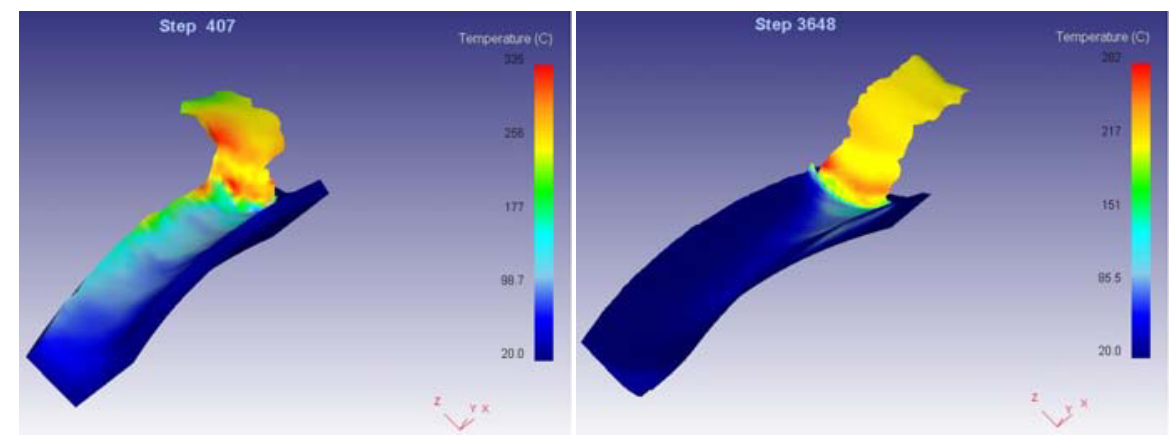

Fig. 2. The modelling outcome - machined material temperature distribution. 


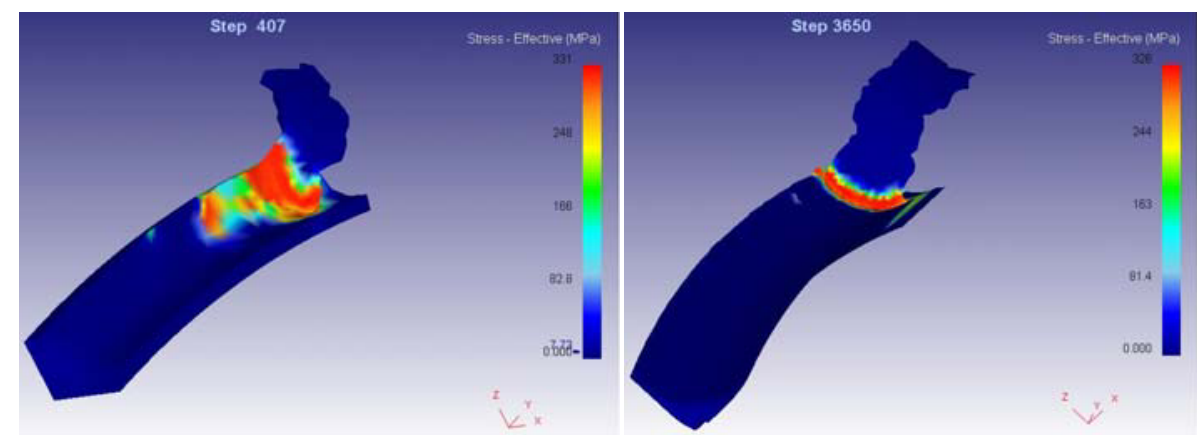

Fig. 3. The modelling outcome - normal stress distribution.

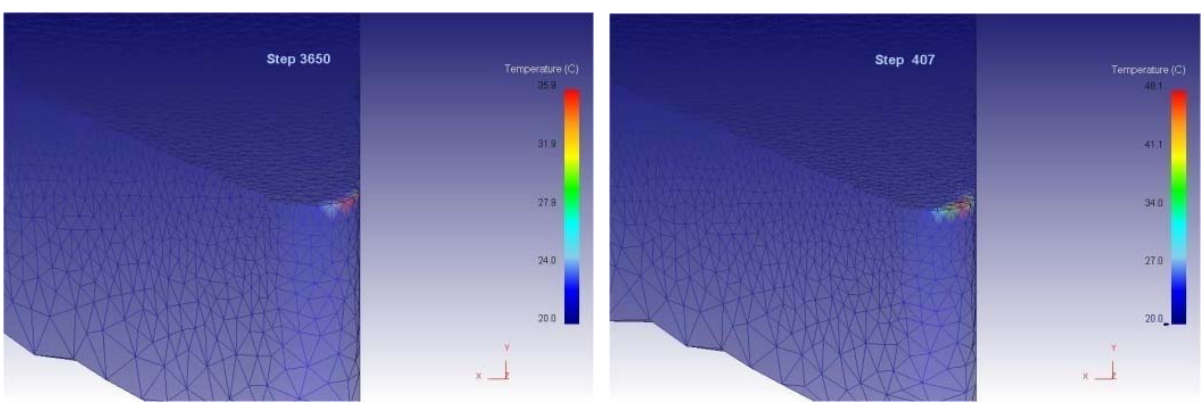

Fig. 4. The modelling outcome - tool cutting edge temperature.

\section{Stereometry measurement on the profilometer}

The top layer condition depends largely on the aluminium alloy type, machining parameters, tooling quality and the machine tool technical condition. With the increase in hardness and strength and the contents of hard inclusions, such as silicon, aluminium alloys are more readily machinable and form short breakable chips. At high machining speeds, a small feed and small machined material layers and with sharp cutting plate edges, additional finishing can be eliminated. Incorrectly selected machining parameters, on the other hand, may cause the formation of accretions on the cutting edge and, as a consequence, a change in its geometry, which will result in a poor surface quality. An essential role is played also by the shape of chips and their evacuation from the machining zone. Unless chips are removed effectively, scratching of the surface and an impairment of its condition may usually be caused. Should a large volume of continuous chips form, an imbalance of the workpiece, damage to the machining tool, or the complete disruption of the machining process may result.

Measurements were taken on a computerized measuring stand consisting of a New Form Talysurf 2D/3D 120 Taylor Hobson profilometer with the 'Ultra Surface 5.21' and 'TalyMap Platinium 5.1.1' software applications, which enables the comprehensive measurement of top layer surface roughness and stereometry parameters in $2 \mathrm{D}$ and $3 \mathrm{D}$ systems with a minimum measuring head resolution of $3.2 \mathrm{~nm}$. The measuring stand is furnished with a table enabling measured surfaces to be precisely moved in the direction perpendicular to the gauging point displacement. It makes it possible to take measurements necessary for the three-dimensional reproduction of the stereometry of the zone in which an irregularity forms as the tool contacts the machined material (aluminium alloy 2017). A gauging tip in the form of a $2 \mu \mathrm{m}$-radius diamond needle was used in the measurements [10]. 
Results from two turning tests performed on a CNC turning lathe are reported. Machining parameters identical to those in the numerical analysis were taken in the tests.

The three-dimensional image of the recorded deformation zone was digitally preprocessed to make it level (Figure 5).

a)

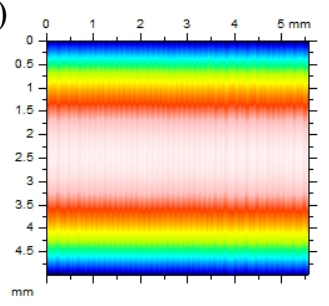

c)

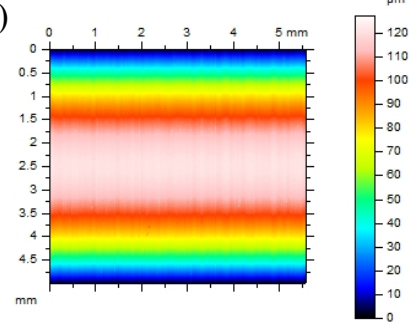

b)

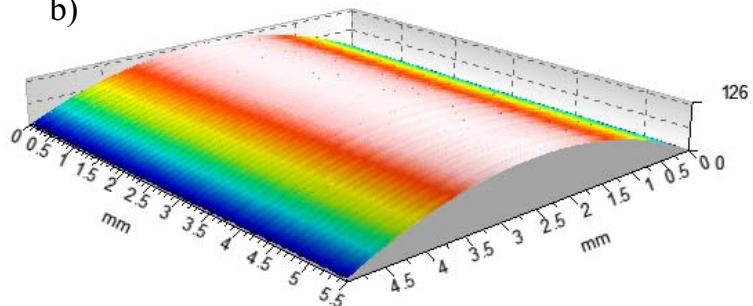

d)

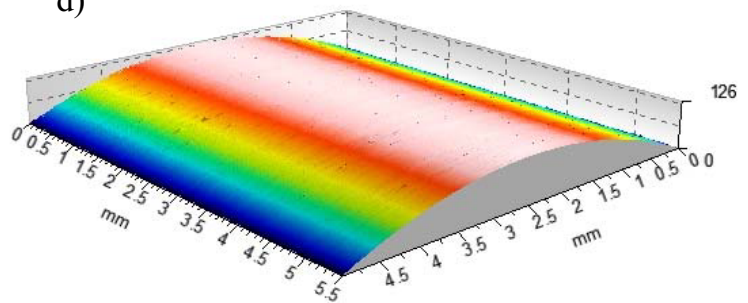

Fig. 5. The stereometry of a selected cylindrical surface area (a, c) a contour line map, (b, d) a 3D view.

The further digital processing of the area under analysis removed the shape component, the cylinder, from the image (Figure 6).

a)

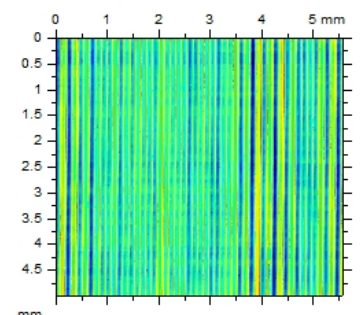

c)

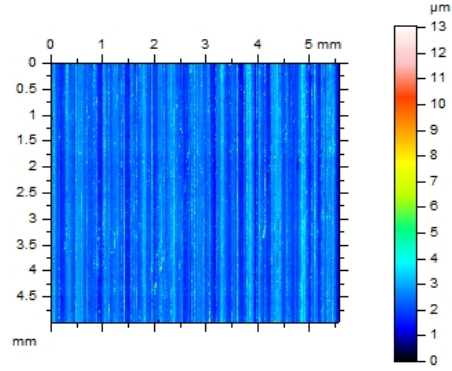

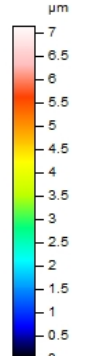

um

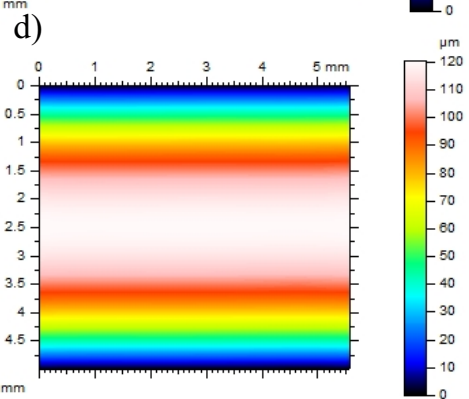

Fig. 6. An image of the stereometry of the selected cylindrical surface area: (a, c) a contour line map of the planar area, $(b, d)$ the cylindrical shape component.

A planar image of the analyzed stereometry was formed. It is also possible to determine the three-dimensional view of the analyzed stereometry (Figure 7). 

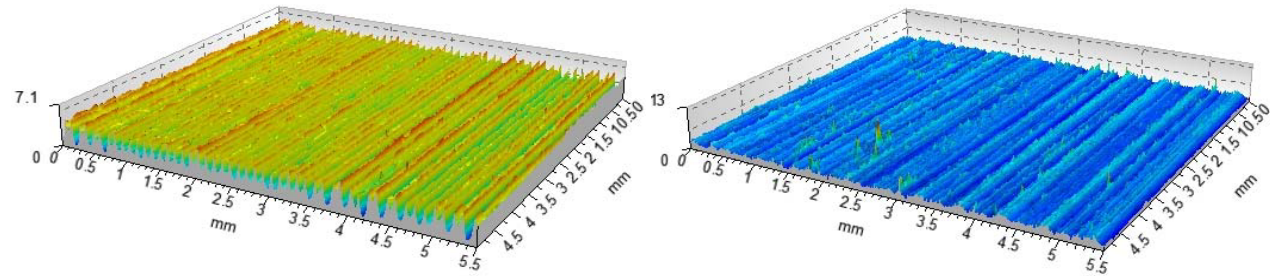

Fig. 7. A three-dimensional image of the selected area stereometry.

The selected parameters of the stereometry of the analyzed area (the height parameters of the first test: $\mathrm{Sa}=0.86 \mu \mathrm{m}, \mathrm{Sq}=1.03 \mu \mathrm{m}, \mathrm{Sz}=7.16 \mu \mathrm{m}, \mathrm{Sp}=4.41 \mu \mathrm{m}, \mathrm{Sv}=2.75 \mu \mathrm{m}$, and the height parameter for the second test: $\mathrm{Sa}=0.40 \mu \mathrm{m}, \mathrm{Sq}=0.54 \mu \mathrm{m}, \mathrm{Sz}=13.10 \mu \mathrm{m}, \mathrm{Sp}=10.70$ $\mu \mathrm{m}, \mathrm{Sv}=2.40 \mu \mathrm{m}$ ), the distribution of the area ordinates and the area load capacity curve were determined.

In addition, for the selected profile, after filtration, the roughness parameters of the analyzed profile (the amplitude parameters for the first test: $\mathrm{Ra}=0.81 \mu \mathrm{m}, \mathrm{Rq}=0.97 \mu \mathrm{m}$, $\mathrm{Rz}=4.03 \mu \mathrm{m}, \mathrm{Rp}=2.35 \mu \mathrm{m}, \mathrm{Rv}=1.68 \mu \mathrm{m}$, and the amplitude parameters for the second test: $\mathrm{Ra}=0.36 \mu \mathrm{m}, \mathrm{Rq}=0.46 \mu \mathrm{m}, \mathrm{Rz}=2.51 \mu \mathrm{m}, \mathrm{Rp}=1.47 \mu \mathrm{m}, \mathrm{Rv}=1.05 \mu \mathrm{m}$ ), as well as the distribution of the profile ordinates and the material ratio curve, can be determined (Figure $8)$.

a)

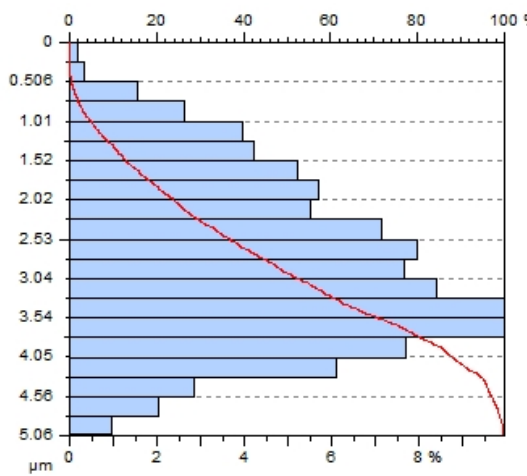

c)

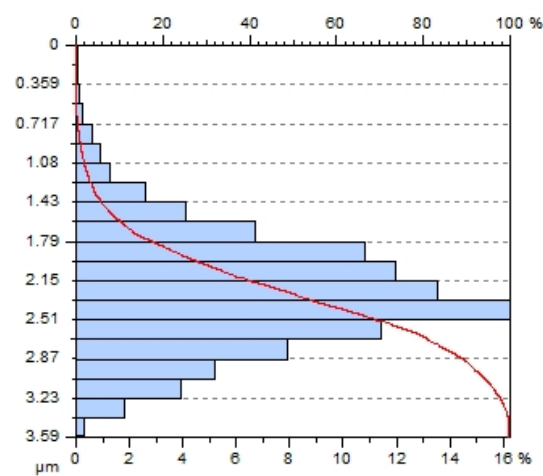

b)

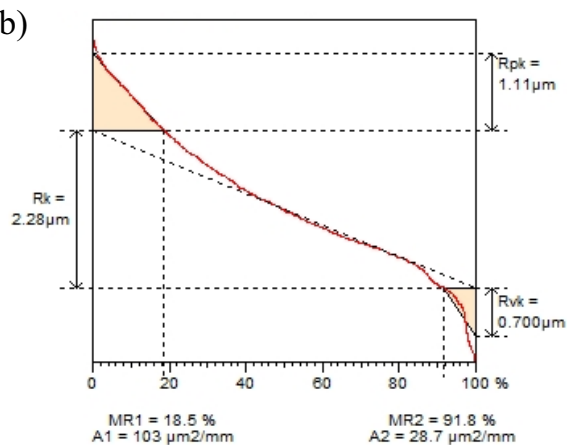

d)

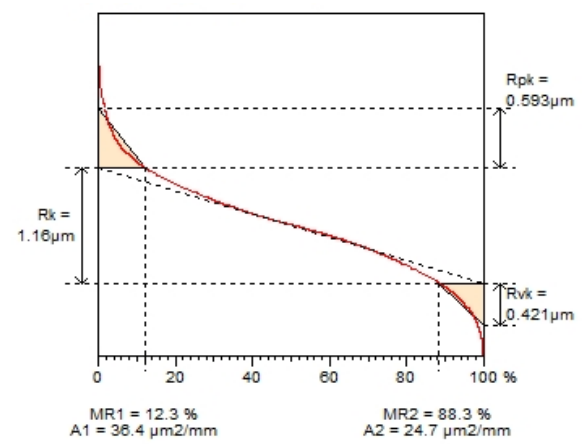

Fig. 8. The distribution of the ordinates (a, c) and the load capacity curve (b, d) for the analyzed profile.

As a complement to the analysis of the examined surface stereometries, microscopic photographs of the formed surface irregularity contours were taken. The photographs were taken utilizing the capabilities of a VMHT MOT laboratory digital microscope. 
The photographs cover the fragment of the top layer area subjected to turning (Figure 9). They confirmed the results of analyses made based on surface stereometry examination.

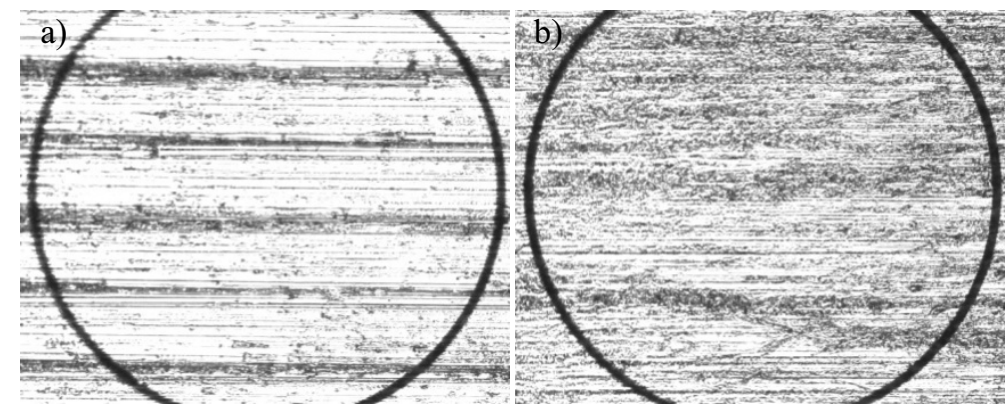

Fig. 9. A microscopic photograph of the turned surface a) $\mathrm{ft}=0.1 \mathrm{~mm} / \mathrm{rev}, \mathrm{b}) \mathrm{ft}=0.01 \mathrm{~mm} / \mathrm{rev}$.

The actual roughness value of the surface machined by turning is, however, dependent on many factors, chiefly on the plastic properties of the machined material, the vibrations of the machine tool-tool system, tool wear, etc. Their impact on the surface roughness is normally determined experimentally. The basic purpose of machining is to shape a new part surface so that it meets the quantity and quality requirements specified by the designer.

\section{Conclusions}

The methods of modelling and simulation of technological processes are becoming essential in the design of technological processes. They allow the saving of time and indicate the direction of practical activities. It is becoming possible to test and verify the correctness of the operation conditions of new machining tools according to the user's own design, with an untypical microgeometry, without having to create them physically.

Aluminium alloys are readily machinable. The analysis showed that selecting high machining speeds, as compared to e.g. steel, did not cause any major increase in turned material temperature (approx. $200^{\circ} \mathrm{C}$ ), its fusion or structural changes. The increase in tool surface temperature is also small. The majority of heat is removed with chips.

By selecting a high machining speed, a small feed and a small material layer, as well as a sharp cutting plate, the additional finishing can be eliminated and a better surface quality can be achieved. A surface with a surface roughness of $\mathrm{Ra}=0.36 \mu \mathrm{m}$ was obtained in the test.

The aim of the present analysis is to enable the control of the duralumin turning process and to optimally select the parameters of technological processes to be carried out, as well as to predict the operation parameters.

\section{References}

1. W. F. Hosford, Physical Metallurgy (CRC Press, Boca Raton, 2010)

2. L.R. Kilmetova, P.V. Sletnev, J. Eng. Sci. Technol. Rev.,7, 5 (2014)

3. M. K. Swamy, B. P. Raju, B. R. Teja, IOSR J. Mech. Civ. Eng., 3, 6 (2012)

4. C. Constantin, S. M. Croitoru, G. Constantin, C. F. Bisu, Advances in Visualization, Imaging and Simulation, Proc. 3rd WSEAS Int. Conference, 10 (University of Algarve, Faro 2010)

5. A. A. Kawi, Al-Qadisiya J. Eng. Sci. 4, 3 (2011)

6. DEFORM 3D User's Manual, (Scientific Forming Technologies Corporation, Columbus, Ohio 2007) 
7. G. R. Johnson, W. H. Cook, 7th Int. Symp. Ballistics (1983)

8. J. Lorentzon, N. Jarvstrat, Arch. Comput. Mater. Sci. Surf. Eng., 1, 1 (2009)

9. Y. R. Bhoyar, P. D. Kamble, Int. J. Mod Eng., 3, 1 (2013)

10. A. Zaborski, Mechanik, 11 (2010) 